\title{
Instructions and interstimulus interval in eyelid conditioning '
}

MARK OMINSKY, DEPARTMENT OF PSYCHOLOGY, DUKE UNIVERSITY, Durham, N. C. $27706^{2}$

A group presented with a relatively short interstimulus interval (ISI) was not as able to inhibit successfully the development of conditioned responses as was a group given a relatively longer ISI when both groups had received inhibitory instructions. This contrasted with approximately equal levels of responding attained by two other groups given the same short and long ISIs but facilitatory instructions.

The effects of set on eyelid conditioning are largely negative ones (Beecroft, 1966). A person who is told to let his reactions take care of themselves usually produces a high level of responding, although inhibitory sets may be found even with neutral or facilitatory instructions (Miller, 1939; McAllister \& McAllister, 1958). McAllister's suggestion, similar to that of Woodworth (1938), was that Ss inhibited responding because they did not want to appear foolish by blinking to the CS before the US was delivered. Instructions to inhibit responding during the CS generally have produced decreased CR levels and even smaller UR amplitudes (Norris \& Grant, 1948; Nicholls \& Kimble, 1964).

As a result of his experiment, Fowler (1964) suggested that inhibitory sets may produce different response levels for interstimulus intervals (ISI) which ordinarily produced equal levels of responding. Furthermore, based on his data with a partial reinforcement schedule, he hypothesized that Ss who are given a relatively longer ISI will be able to mobilize their inhibitory set more easily than will those with a relatively shorter ISI. This experiment will test that hypothesis.

Method. The Ss were 60 nursing students who volunteered to fulfill the requirements of the introductory psychology course. They were placed at random into one of four groups of a 2 by 2 factorial design in which instructions (facilitatory and inhibitory) and interstimulus interval $(.4 \mathrm{sec}$ and $1.1 \mathrm{sec})$ defined the marginals. Each $\mathrm{S}$ received a set of instructions (either facilitatory or inhibitory) and one CS-US interval (short or long). Instructions to the facilitatory group included: " . . . relax and let your eyes' reactions take care of themselves. In other words try to forget about your blinking altogether.." The inhibitory group was instructed to: "... try to inhibit your blinking whenever you see the light (CS). In other words try not to blink while the light is on."

The laboratory was the same as that described elsewhere (Ominsky \& Posnick, 1968). All Ss received their instructions directly from the experimenter in the soundproof chamber. The $S$ then received five preliminary trials consisting of three CSs (a red light) and two USs (a $180 \mathrm{~mm} \mathrm{Hg}$ airpuff). This was followed by 60 CS-US trials and 10 extinction trials.

The definition of the CR was derived from Fowler (1964) and Boneau (1958). Boneau determined those latencies of responses which tended to increase over trials for various CS-US intervals. These responses, which he found to fall into the last 33-40\% of the interval, were then designated as CRs. Fowler adopted a similar criterion and confirmed its use by his latency distributions. Since the present experiment utilized the same ISIs as Fowler, his latency criteria were adopted. These were $240-425 \mathrm{msec}$ for the short (400 msec) CS-US interval and $660-1125 \mathrm{msec}$ for the long (1100 msec) interval.

Results. Figure 1 contains conditioning curves of the four groups plotted with percentage of CRs on the ordinate and blocks of 10 trials on the abscissa.

A three-factor analysis of variance (Case 2 in Winer, 1962) was performed. The analysis reveals that the main factor of instructions was highly significant $(F=14.77$, df $=1 / 56, \mathrm{p}<.001)$, indicating that, overall, Ss who received inhibitory instructions conditioned to a much lower level than did those with facilitatory instructions. The trials factor was also highly significant ( $\mathrm{F}=$ 26.28 , df $=5 / 280, p<.001$ ), reflecting the overall increase in conditioning during acquisition. The interval by trials interaction also attained significance $(F=3.44$, df $=5 / 280, p<.01)$.

An analysis of the simple effects showed that instructions were significant at both $.4 \mathrm{sec}$ and $1.1 \mathrm{sec}$ ISIs $(F=4.92, \mathrm{df}=1 / 56$, $\mathrm{p}<.05$ and $\mathrm{F}=10.35$, df $=1 / 56, \mathrm{p}<.01$, respectively). This means that inhibitory instructions significantly lowered the level of conditioning overall for both the $.4 \mathrm{sec}$ and the $1.1 \mathrm{sec}$ groups. According to an analysis of the simple effects of the trials factor, all groups significantly increased over trials.

A second analysis was performed for the last 20 conditioning trials in order to clarify what was occurring at the end of acquisition. We again found that the effect of instructions was significant $(p<.05)$, but now an analysis of the simple effects indicated that inhibitory instructions were effective only for the long ISI group $(F=5.74, \mathrm{df}=1 / 56, \mathrm{p}<.05)$ and not for the short ISI group $(F=1.40, \mathrm{df}=1 / 56)$.

An analysis of variance of the extinction data showed that the effect of inhibitory instructions was highly significant $(p<.001)$ but interval was not. An analysis of the simple effects demonstrated that inhibitory instructions led to a faster extinction than facilitatory ones for both the short and long ISIs.

Discussion. The outcome of this experiment confirmed the results obtained so frequently in the past (from Miller, 1939, to Nicholls \& Kimble, 1964) that inhibitory sets induced through instruction have a powerful effect on conditioning. It supplements previous findings, however, by showing that the magnitude of this effect is greater at relatively longer CS-US intervals than at short ones.

Our finding with respect to percentage of CRs parallel those of Fowler. There was no difference between $\mathrm{Ss}$ conditioned at a relatively short ISI $(.4 \mathrm{sec})$ and those conditioned at a relatively long ISI $(1.1 \mathrm{sec})$ when facilitatory instructions were given; however there was a difference when inhibitory instructions were used. We found that inhibitory instructed groups were not able entirely to block successfully the opposing tendency to produce CRs.

The course of the acquisition function for the short interval inhibitory group suggests that these Ss have a very difficult time carrying out their instructions. Two possibilities are evident. Either Ss keep trying to inhibit but are less able to do so, or they finally abandon the inhibitory set when they encounter difficulty exercising it. Extinction data along with a post-experimental

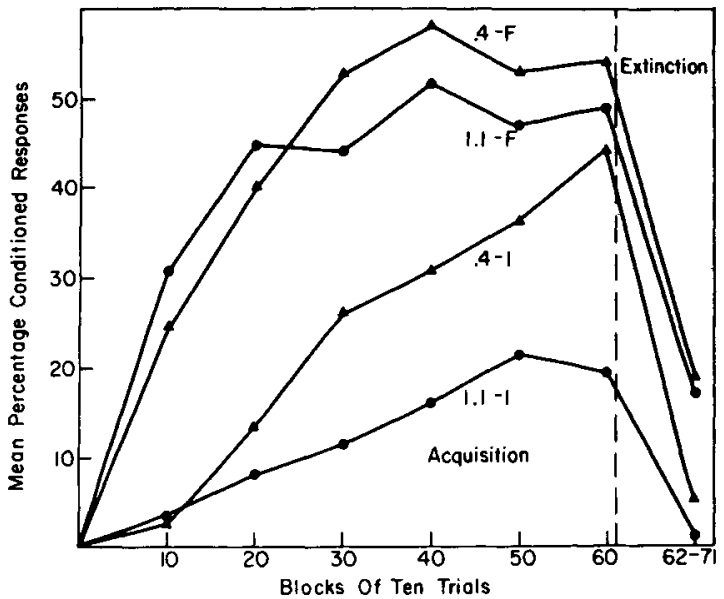

Fig. 1. Percentage of CRs during acquisition and extinction for all groups in blocks of 10 trials: $.4 \mathrm{sec}$ Facilitatory (.4 F), $1.1 \mathrm{sec}$ Facilitatory (1.1 F), .4 sec Inhibitory (.4 I), $1.1 \mathrm{sec}$ Inhibitory (1.1 I). 
discussion suggest that the latter is probably not the case. In extinction both the long and the short ISI groups dropped immediately to the same low level, despite the fact that there was a significant difference between them on the last block of acquisition trials. Although the short ISI group may have readopted an inhibitory set once extinction began, it is more likely that they were continuing the inhibitory set which they held throughout acquisition. Informal comments from Ss in the short interval groups seemed to confirm this hypothesis.

How then can one explain the poor inhibition of the short ISI inhibitory group? It is evident that Fowler's suggestion that Ss conditioned with a short ISI are not given enough time to inhibit their responses was not confirmed. In extinction this group was, in fact, immediately able to decrease its responding to the level of the long ISI inhibitory groups and significantly below the levels of the two facilitatory groups, indicating that Ss do have sufficient time to inhibit responding. One possible explanation concerns the countereffect by the US on inhibitory set. The hypothesis is that the closer the US is to the onset of the CS, the greater interference it will have on an attempt to inhibit responding. This interfering effect builds up gradually, just as does conditioning, and results in the eventual masking of the effects of inhibitory set. In line with our hypothesis is Pavlov's view of internal inhibition as interpreted by Kimble (1967): " . . . Pavlov regarded internal inhibition as (a) involving a temporary connection which was (b) just as fragile as the connection of excitatory elements. Where nonreinforcement destroys the excitatory connection, reinforcement destroys the inhibitory one [p. 37]."

\section{REFERENCES}

BEECROFT, R. S. Classical conditioning. Goleta, California: Psychonomic Press, 1966.
BONEAU, C. A. The effect of changing the interstimulus interval on the conditioned eyelid response. Unpublished doctoral dissertation, Duke University, 1958.

FOWLER, W. R. The interstimulus interval and schedule of reinforcement in eyelid conditioning. Unpublished doctoral dissertation, Duke University, 1964.

KIMBLE, G. A. Attitudinal factors in eyelid conditioning. In G. A. Kimble (Ed.), Foundations of conditioning and learning. New York: AppletonCentury-Crofts, 1967.

McALLISTER, W. R., \& McALLISTER, D. E. Effect of knowledge of conditioning upon eyelid conditioning. J. exp. Psychol, 1958, 55, 579-583.

MILLER, J. The effect of inhibitory and facilitatory attitudes on eyelid conditioning. Unpublished doctoral dissertation, Yale University, 1939. (Cited by E. R. Hilgard and D. G. Marquis, Conditioning and leaming. New York: Appleton-Century-Crofts, 1940.)

NICHOLLS, M. F., \& KIMBLE, G. A. Effect of instructions upon eyelid conditioning. J. exp. Psychol, 1964, 67, 400-402.

NORRIS, E. B., \& GRANT, D. A. Eyelid conditioning as affected by verbally induced inhibitory set and counter reinforcement. Amer. J. Psychol, 1948, 61,3749 .

OMINSKY, M., \& POSNICK, G. M. The effect of paired neutral stimuli on the acquisition and extinction of the classical eyeblink response. Psychon. Sci. 1968, 10, 67-68.

WINER, J. Statistical principles in experimental design. New York: McGraw-Hill, 1962.

WOODWORTH, R. S. Experimental psychology. New York: Holt, 1938. NOTE

1. Based on a dissertation submitted in partial fulfillment of the requirements for the Ph.D. degree at Duke University and supported in part by Research Grant MH-08090 from NIH to Dr. Gregory A. Kimble. The author wishes to thank Dr. Kimble for his support and guidance.

2. Presently at IBM, Endicott, N.Y. 